\title{
Who empowers whom? \\ The role of organizational health literacy in empowering patients ${ }^{1}$

\section{Carmela Annarumma - Rocco Palumbo - Mauro Cavallone}

\begin{abstract}
Purpose of the paper: This paper aims to explore the organizational health literacy of pharmacies, which are believed to perform as critical patient navigators in the health care arena. Organizational health literacy is understood as the ability of health care organizations to establish clear and comfortable relationships with their patients, involving them in a co-creating partnership.

Methodology: A comparative research design was arranged. Two convenience samples of pharmacies operating in two regional sub-systems of the Italian National Health Service (INHS) were built. Sixty units of analysis were included in the study; their organizational health literacy was examined in absolute and comparative terms.

Results: The units of analysis were aware of their role in enabling patients, but they did not conceive organizational health literacy as being either a strategic or a managerial tool to enhance their ability to empower patients and engage them in value co-creation.

Research limitations: Since the research concerned two convenience, nonrepresentative samples, it is not possible to claim the findings' generalizability.

Practical implications: Organizational health literacy should be conceived as a core idea inspiring pharmacies' activities. In particular, health literacy should be dealt with as a driver to raise the awareness of the pharmacy's role in enhancing the effectiveness and the appropriateness of care.

Originality of the paper: The scientific literature has focused most of its attention on the process of patient enablement; in contrast, the role of health care organizations in empowering patients has been overlooked. This is one of the first attempts to examine the organizational health literacy of pharmacies, investigating their ability to perform as patients' navigators.
\end{abstract}

Key words: organizational health literacy; health literacy; health communication; patient-centered care; pharmacies

\section{Introduction: framing patient empowerment in the health literacy perspective}

Patient empowerment has been discussed as an innovative paradigm inspiring the provision of care. Indeed, it involves a “... fundamental redefinition of roles and relationships of health care professionals and

Best paper for the 19th Toulon-Verona Conference "Excellence in Services University of Huelva in Andalucia, Spain, 5-6 September 2016. 
sinergie Vol. 35, N. 104, 2017

patients" (Anderson and Funnell, 2005, p. 153). Patients are encouraged to develop and apply a comprehensive set of health-related skills and abilities, which allow them to perform as value co-creators (Funnell et al., 1991). Self-determination and personal change are the main ideas at the basis of patient empowerment (Aujoulat et al., 2007): education and information boost patients' ability to deal with health-related issues and to participate in the provision of health services (Bravo et al., 2015).

Prigge and co-authors (2015) recently examined the antecedents of patient empowerment, pointing out that the enhancement of individual health-related competencies is critical for achieving patient involvement and improving self-efficacy perception. From this point of view, health literacy - that is to say "... the degree to which individuals have the capacity to obtain, process, and understand basic health information and services needed to make appropriate health decisions" (Baker, 2006, p. 878) - is assumed to be a requisite to patient empowerment (Palumbo et al., 2016a, 2016b). Several authors claimed that patient empowerment initiatives may be counterproductive when addressed to people with limited health literacy (Wang et al., 2016). Even though health literacy and patient empowerment may be depicted as independent concepts (Camerini and Schulz, 2015), the impacts produced by them are strictly intertwined (Schulz and Nakamoto, 2013).

To the authors' knowledge, both scholars and practitioners have concentrated their attention on the patient when depicting the attributes and the consequences of patient empowerment initiatives, focusing on: the states which allow patient involvement, the processes which lead to patients' enablement, and the behaviours through which patients participate in the provision of care (Palumbo, 2016a: Fumagalli et al., 2015). In contrast, the role of health care organizations in empowering patients and in stimulating their engagement in the delivery of care has been overlooked (Willis et al., 2014).

Organizational health literacy is rapidly growing as an effective approach to serve high need populations and to improve patients' ability to navigate the health care service system (Weaver et al., 2012). Organizational health literacy may be understood as the ability of health care organizations to establish a friendly and co-creating partnership with patients, encouraging them to be involved in the provision of health services (Palumbo, 2016b). Brach and colleagues (2012) identified ten attributes which suggest the adoption of a health literacy approach in structuring health care organizations. In particular, a health literate health care organization: 1) has a style of leadership which makes health literacy integral to its mission, structure, and operations; 2) includes health literacy in its managerial actions, including planning, evaluation, patient safety, and quality improvement; 3) stimulates awareness of the consequences of limited health literacy on health outcomes; 4 ) encourages the participation of the population served in the design and delivery of care; 5) strives to meet the needs of the underserved population, overcoming stigma; 6) uses health literacy strategies in interpersonal communications at all points of contact with patients; 7) supports patients in navigating the health care system; 8) provides, designs and distributes print and audio-visual materials that 
are easy to understand; 9) help patients in high-risk situations, including care transitions and communications about medicines; 10) communicates in a friendly and clear way what health plans cover and what services are financed out-of-pocket.

Organizational health literacy has been described as a flexible approach, which could be adapted to different kinds of health care organizations (Annarumma and Palumbo, 2016; Hernandez, 2013). Among others, pharmacies have been found to play a critical role in supporting patients to properly function within the health care service system (Palumbo and Annarumma, 2015). In fact, pharmacists are likely to perform as trusted patient navigators, as they are able to grasp the information needs of the latter and fill their knowledge gaps (Rosenthal et al., 2014). Echoing these considerations, the scientific literature has variously claimed that pharmacists are able to help patients in handling complex drug regimens, play a critical role in inciting the self-management of care and encouraging significant life-style changes; they provide patients with support and counselling to comply with medical prescriptions and foster patient involvement in the provision of care (Collins et al., 2014; Johnson, et al., 2013; Jennings and McAdam Marx, 2012; Abramowitz, 2009). Furthermore, the ability of pharmacists to meet patients' information needs has been considered as a predictor of increased relationship commitment between the patients and the health care service system which, in turn, produces better health outcomes (Alghurair et al., 2012).

Drawing on these arguments, this paper has a twofold purpose. On the one hand, it is aimed to explore whether organizational health literacy is understood as a strategic tool by pharmacies; on the other hand, it examines what kinds of initiatives are arranged and implemented by pharmacies in order to enhance organizational health literacy. A comparative approach was adopted in an attempt to identify either similarities or dissimilarities in the behavior of pharmacies operating in different health care sub-systems.

This paper is organized as follows: the second section briefly depicts the study's research design and methodology, providing some details on the two convenience samples which were built for the purpose of this research; moreover, the tools which were used to assess the pharmacies' organizational health literacy are described. The third section summarizes the main findings of the research, emphasizing that pharmacies could adopt different approaches to increase their organizational health literacy and involve patients in a co-creating relationship. The findings of the study are critically discussed in the fourth section, which paves the way for interesting conceptual and practical implications. The concluding section summarizes the relevance of this research, discussing organizational health literacy as a fundamental ingredient of the recipe for patient empowerment.

\section{Research design and methods}

A comparative research design was developed and implemented for the purpose of this study (Boddewyn, 1970). Such a comparative approach allowed to delve into the novelty of the topic investigated, leading to a more
Carmela Annarumma

Rocco Palumbo

Mauro Cavallone

Who empowers whom?

The role of organizational

health literacy in empowering patients 
sinergie Vol. 35, N. 104, 2017

reliable understanding of pharmacies' awareness of organizational health literacy issues. Sticking to the prevailing literature (George, 1979), a focused and structured research method was devised. On the one hand, attention was concentrated on the organizational health literacy skills of pharmacies; on the other hand, a structured approach to assess the pharmacies' ability to establish a friendly and comfortable relationship with their users was embraced.

In line with the exploratory nature of this study, a theoretical sampling drove the selection of the units of analysis (Fox-Wolfgramm, 1997). Two convenience samples of both municipal and private pharmacies operating in two different regional sub-systems of the Italian National Health Service (INHS) were built. One sample consisted of thirty pharmacies operating within a health care sub-system suffering from financial distress and whose governance model was mainly inspired by New Public Management principles (Sarto et al., 2016). The second sample consisted of thirty pharmacies operating in a virtuous regional sub-system steered according to a Public Governance approach (Bovaird and Löffler, 2009). In total, sixty units of analysis were included in this study. Their organizational health literacy skills were examined in both absolute and comparative terms.

To assess the organizational health literacy levels of the units of analysis, a self-reporting survey was drawn up, based on the Health Literacy Assessment Tool which was devised by the US Agency for Healthcare Research and Quality (AHRQ) to evaluate the ability of pharmacies to meet patients' information and knowledge needs (Jacobson et al., 2007). In particular, the Health Literacy Assessment Tool aims to assess the health literacy-related readiness of pharmacies from three different points of view: environment, patients, and staff (O'Neal et al., 2013). In light of the specific purposes of this study, neither the environment nor the patient perspectives were contemplated to assess the organizational health literacy of the units of analysis. Rather, attention was focused on staff perspective, with the specific intent of appreciating the awareness of organizational health literacy-related issues on the part of the pharmacies' employees.

The items of the self-reporting survey concerned three conceptual domains related to organizational health literacy: 1) the accessibility of printed information materials; 2) the friendliness of interpersonal communication between the pharmacy staff and patients; and 3) pharmacy staff sensitivity to health literacy-related issues. The original English version of the assessment tool was independently translated into Italian by two scholars with competence in the field of health management. The translation from English to Italian was realized in light of the institutional and organizational peculiarities of the INHS. The two drafts of the translated survey were duly compared, in order to identify any divergences and to settle them. Whenever the translators were unable to settle their disagreements, a third independent scholar was invited to participate in the discussion in an attempt to reach an agreed solution. The final draft of the Italian survey was translated back to English by a native English speaker, in order to check its consistency with the original version of the questionnaire. A pilot test was performed involving three pharmacies which were not included in the two convenience samples, but showed 
comparable characteristics with the units of analysis. The respondents were asked to fill in the survey and to disclose their perceived meaning for each item of the tool. The pilot test results highlighted several minor issues concerning a few items of the survey, which were resolved in light of the respondents' comments.

A formative model was adopted, according to which the three latent constructs of the self-reporting survey were determined as a combination of different items (Coltman et al., 2008). It was assumed that: the items defined the constructs; the items were not interchangeable; any variation in the layout of the questionnaire implied significant changes in the conceptual domains of the constructs (Diamantopoulos and Siguaw, 2006). The final version of the survey consisted of 35 items, which were asymmetrically distributed within the three conceptual domains: 9 items formed the "print materials" section; 11 items were included in the "clear verbal communication" area; and 15 items constituted the "sensitivity to literacy" domain.

Drawing on the original version of the Health Literacy Assessment Tool (O'Neal et al., 2013; Jacobson et al., 2007), a 9-point Likert scale was attached to each item of the survey: values close to 1 indicated a strong disagreement with the statement reported in the item, while values close to 9 revealed a strong agreement with it. Several items of the questionnaire were reversed, for the purpose of minimizing any risks of "response set" (Weijters et al., 2010); the risk of misresponse to reversed items was taken into consideration when examining the collected data (Swain et al., 2008). The units of the analysis that showed a tendency to answer a series of questions by following a preconceived schema were excluded from the analysis.

The survey was addressed to a single key informant for each unit of analysis. The pharmacy's senior manager was identified as the preferred respondent. Whenever he or she was unable to participate in the study, a substitute employee of the pharmacy was approached, taking length of service and organizational position as the main eligibility criteria. The respondents' average age was 42 ; they had a length of service ranging from 4 to 18 years. Approximately two out of three respondents were female. Most of the key informants were in charge of the management of the pharmacy. Less than one out of four respondents were pharmacy clerks. All of the members of the sample were doctors of pharmacy.

\section{Findings}

\subsection{The pharmacies' awareness of organizational health literacy issues}

Interestingly, all the units of analysis showed significant awareness of health literacy-related issues. As depicted in Figure 1, the pharmacies involved in the two convenience samples self-reported - on the average - adequate health literacy levels for the three conceptual domains of the survey, that is to say "print materials", "verbal communication", and "sensitivity to literacy".
Carmela Annarumma

Rocco Palumbo

Mauro Cavallone

Who empowers whom?

The role of organizational

health literacy in

empowering patients 


\section{sinergie}

Vol. 35, N. 104, 2017
Fig. 1: Average scores for "print materials", "clear verbal communication", and "sensitivity to literacy" sections $(n=60)$

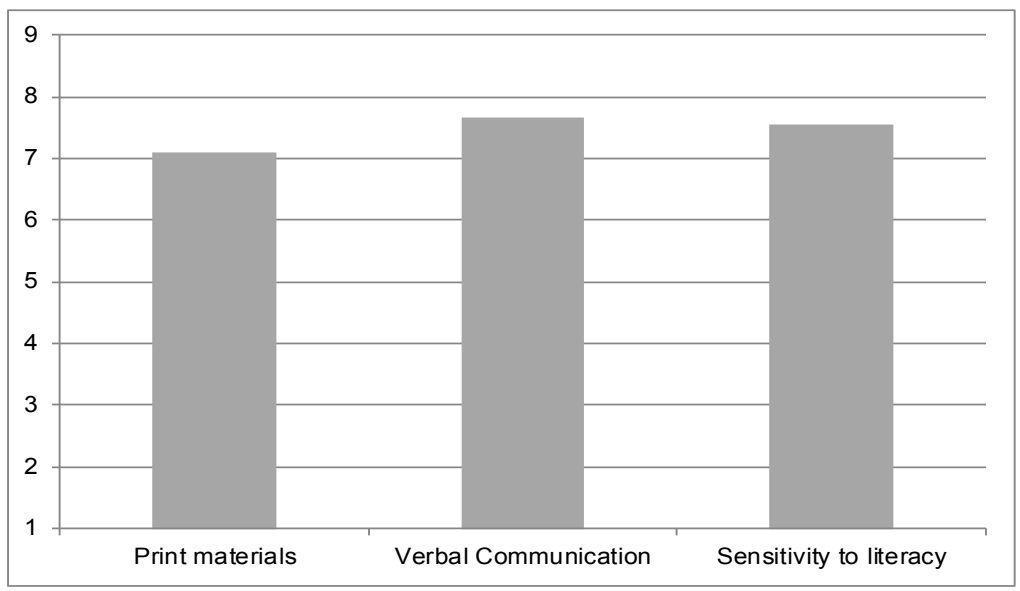

Source: Authors' elaboration

The pharmacies showed the highest average value in the "verbal communication" section $(\mu=7.65 ; \sigma=0.72)$. On the one hand, the respondents were consistent in claiming that they were aware of the difficulties met by patients in navigating the health care service system. From this point of view, the establishment of a friendly and comfortable relationship with patients was widely presented as a critical approach to support patients in effectively accessing, collecting, and understanding relevant health information for the purposes of health protection and promotion. Also, the units of analysis revealed a high sensitivity to literacy ( $\mu=7.55 ; \sigma=0.67)$, identifying problems incurred by patients in fully understanding and complying with clinical prescriptions as the most important determinant of poor health outcomes. The scores achieved in the "print materials" section $(\mu=7.10 ; \sigma=0.31)$ were high, but they were lower compared with both "verbal communication" and "sensitivity to literacy". In short, it could be argued that - in spite of the significant awareness of health literacy on the part of the units of analysis - several barriers prevented pharmacies from designing and implementing an organizational health literate environment.

The two samples revealed several peculiarities which suggested a potential influence of institutional variables and contingent factors on the pharmacies' willingness and ability to deal with health literacy-related issues. As illustrated in Figure 2, Convenience Sample 2, that is to say the pharmacies that operated in a virtuous regional sub-system of the INHS, were likely to disclose higher self-reported awareness of health literacy issues. This was true for all the conceptual domains of the survey. The units of analysis that belonged to the regional sub-system suffering from financial distress (Convenience Sample 1) showed diluted sensitivity to organizational health literacy as well as lower attention to the design and implementation of an organizational health literate environment. 
Fig. 2: Average scores for "print materials", "clear verbal communication", and "sensitivity to literacy" sections for Convenience Sample $1(n=30)$ and Convenience Sample $2(n=30)$.

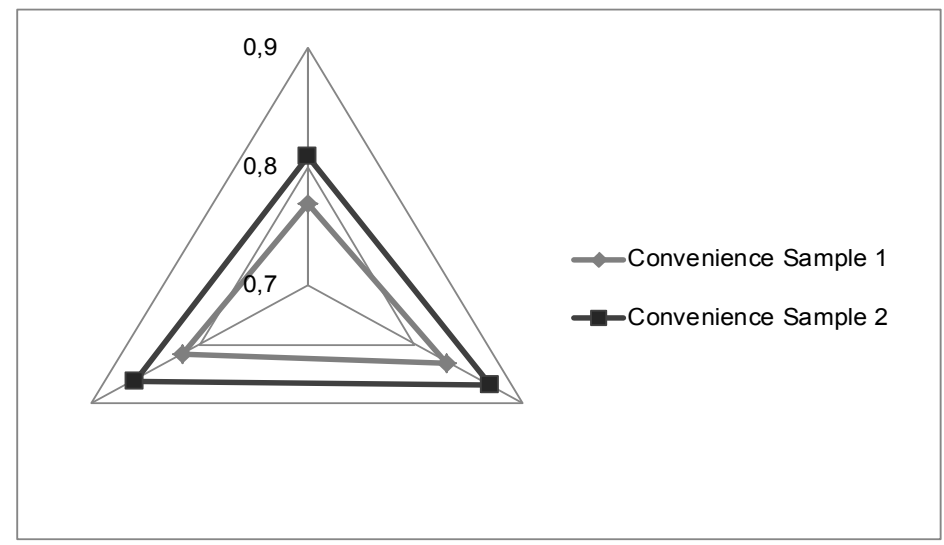

Carmela Annarumma Rocco Palumbo Mauro Cavallone Who empowers whom? The role of organizational health literacy in empowering patients

Source: Authors' elaboration

Figure 3 provides a detailed description of the behaviors of the two convenience samples. On the one hand, Convenience Sample 1 exhibited more common inconsistencies among the different shades of organizational health literacy. In most of the cases, the pharmacies of the regional sub-system suffering from financial distress were likely to pay significant attention to the arrangement of clear verbal communication approaches in order to improve their ability to establish a co-creating relationship with patients. However, such thoughtfulness towards health literacy did not seem to be echoed in terms of both designing friendly and easy to understand print materials or of sensitivity to organizational health literacy-related issues. On the other hand, the units of Convenience Sample 2 showed greater consistency in the scores for the three conceptual areas of the survey. The pharmacies that disclosed high sensitivity to organizational health literacy were consistent in reporting greater propensity to use tailored communication strategies and friendly print materials to assist patients in navigating the health care environment. In contrast, pharmacies disclosing limited sensitivity to organizational health literacy issues were more likely to neglect the role of easy-to-understand written and oral information to improve patients' ability to deal with health-related issues.

In sum, all of the units of analysis were found to be aware of the importance of organizational health literacy in designing a supportive and effective health care environment. This result did not seem to be affected by the contingency factors of the two regional sub-systems that were taken into consideration for the purpose of this study. Nonetheless, the pharmacies that operated in the virtuous regional sub-system were more willing to adopt an organizational health literacy perspective in designing oral and print communication materials. The units of analysis belonging to the regional sub-system suffering from financial distress self-reported greater propensity to use specific communication strategies in order to 
help their patients in navigating the health care arena. On the contrary, they paid only limited attention to the role played by print information materials in improving their organizational health literacy. In line with these considerations, the two samples disclosed different approaches and accounted for different initiatives to enhance pharmacies' organizational health literacy.

Fig. 3. Average scores by units of analysis ( $n=60)$ for "print materials", "clear verbal communication", and "sensitivity to literacy"
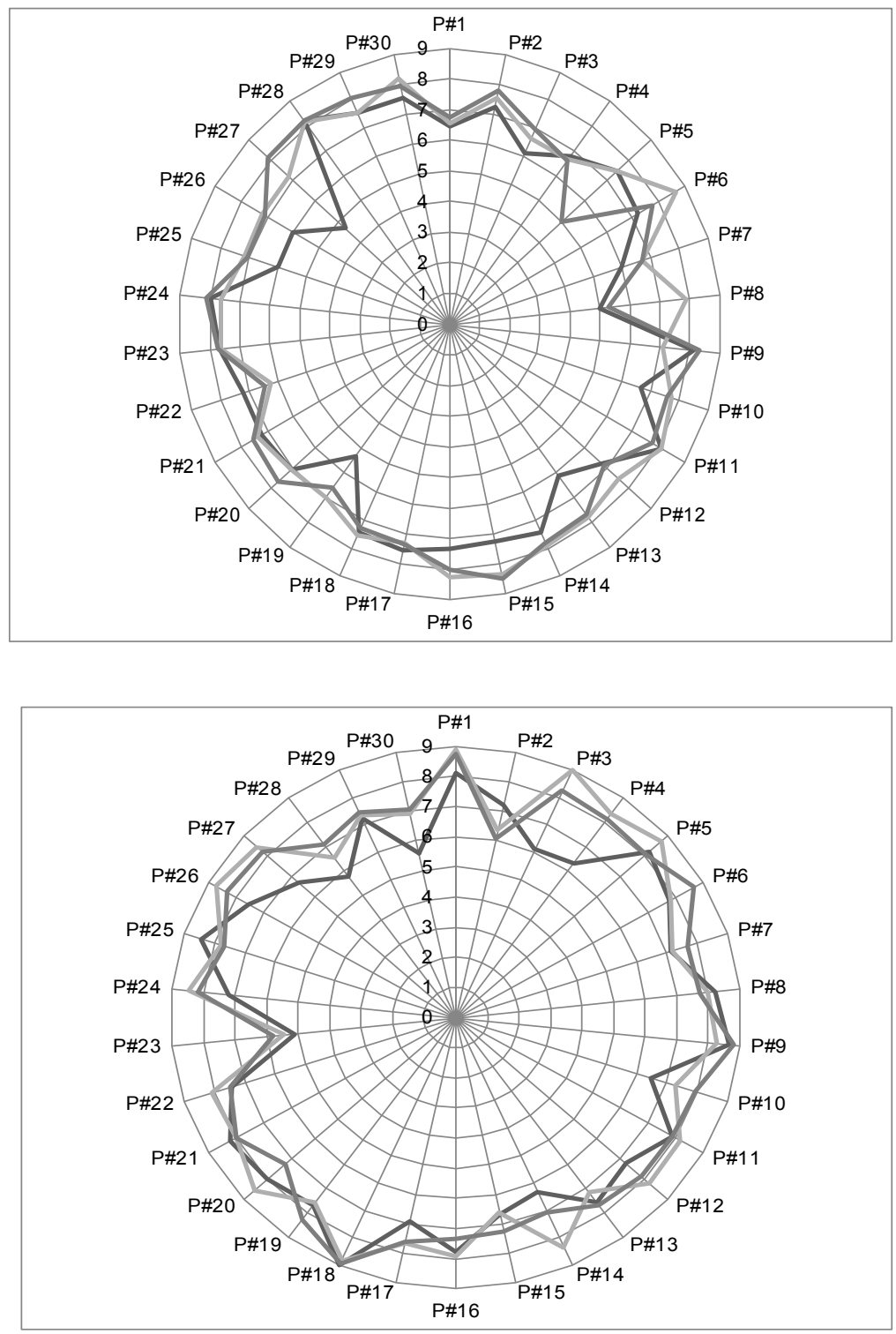

Source: Authors' elaboration 
The pharmacies were consistent in reporting that they had devised tailored and effective signage to support patients in navigating the health literacy in organizational environment. Moreover, the pharmacies' employees perceived that people living with limited health literacy were not likely to ask health care professionals for additional information when they were concerned about a health-related issue. From this point of view, the adoption of an organizational health literacy approach in arranging print information materials was assumed to prevent the risks of patients' confusion and misunderstanding. In most of the cases, the organizational layout of the pharmacies was designed in light of the specific information needs of the served population, in order to allow patients' better access to the services offered by the pharmacy.

Print information materials were primarily aimed at providing patients with useful information about timely health topics; in addition, ongoing health-related issues were depicted in posters and brochures, which were devised according to both national and international guidelines. Also, the units of analysis were consistent in claiming that the language they used for the design of health information materials was familiar, clear, and free of jargon, in an attempt to increase patients' ability to understand and process health information. Interestingly, only a few pharmacies reported using either tables or graphs to enhance the comprehensibility of health information materials. In other words, print information materials mainly consisted of text, with limited use of images and charts to assist patients in processing and interpreting health information.

While the units of analysis of Convenience Sample 2 stated that they used both pamphlets and brochures to inform patients about the offered services, the pharmacies included in Convenience Sample 1 were not likely to do so. In addition, in Convenience Sample 1 the pharmacy staff was not encouraged to participate in specific training courses aimed at improving their ability to design and communicate friendly print information materials. Conversely, the units of analysis of Convenience Sample 2 were more engaged in encouraging their workforce to attend training courses $(\mu \mathrm{CS} 2=7.13$ vs. $\mu \mathrm{CS} 1=6.97)$.

In general terms, the units of analysis were aware of the importance of identifying an organizational delegate who is entrusted with tackling problems concerning print information materials. On the whole, only 14 out of 60 units of analysis stated that encountered difficulties in identifying such a delegate. This was especially true for the units of analysis of Convenience Sample 2, which showed greater difficulty $(\mu=6.53)$ as compared with the units of Convenience Sample $1(\mu=7.03)$ in assigning the responsibility to increase the friendliness of print information materials to a member of the pharmacy staff. Both the pharmacies that operated in the regional sub-system suffering from financial deprivation and those that operated in the virtuous one encouraged their staff to use plain and clear language to explain medical jargon and clinical issues to the patients $(\mu \mathrm{CS} 1=7.73$ vs. $\mu \mathrm{CS} 2=8.40)$. Most of the units of analysis pointed out that front-office employees were used to checking patients' understanding 
sinergie Vol. 35, N. 104, 2017

of the health information provided by using the teach-back method, that is to say by asking them to repeat the key points of the communicated messages. To improve their communication strategies and be more effective in interacting with patients, pharmacy employees were likely to assess whether patients were aware of the main health problem they were facing and of the importance of medication adherence in effectively managing their health-related problems.

While the units of analysis of Convenience Sample 2 revealed that they had a private space within the pharmacy where confidential information could be discussed with patients, this was not true for the units of analysis of Convenience Sample 1. However, only 22 out of 60 units of analysis selfreported to be able to effectively manage the relationship with patients for whom Italian was a second language. In addition, the pharmacy staff was usually argued to be unable to meet the information needs of non-Italian speaking patients. Lastly, the senior management of the pharmacies was not likely to launch specific policies intended to increase employees' awareness of organizational health literacy issues or to arouse their willingness to deal with them. This was particularly true with regard to Convenience Sample 1 , whose scores $(\mu=6.97)$ highlighted a weak commitment on the part of their senior management towards the promotion of these policies.

In sum, all of the units of analysis showed significant sensitivity to organizational health literacy. Actually, most of the respondents agreed in declaring that patients' health literacy skills played an important role in improving their medication adherence and their compliance with clinical prescriptions. In line with these considerations, pharmacy employees were consistent in maintaining that their activity did not solely concern the delivery of drugs and medications. Rather, they operated as crucial patient navigators, supporting them in properly handling health information.

The respondents indicated several circumstances in which the pharmacy staff had to pay particular attention to the patients' health literacy skills, since inadequate understanding of health information could pave the way for negative consequences on health outcomes. First of all, the changes in the health treatments that were prescribed to patients were considered as critical events entailing a significant risk due to impaired compliance and poor medication adherence: the lower the health literacy skills of patients, and the poorer the organizational health literacy of health care settings, and the higher the risks that the change in health treatments could turn into reduced medication adherence and poorer health outcomes. Relevant differences between the convenience samples were registered in handling changes in health treatments and in coping with patients suffering from financial deprivation; in both circumstances, the units of Convenience Sample 1 performed worse than Convenience Sample 2. In addition, patients' anger and irritation towards the functioning of the health care system was found to be difficult to manage by the pharmacy staff in both convenience samples.

As compared with the units of analysis of Convenience Sample 2, the pharmacies that operated within the regional sub-system suffering from financial distress pointed out several difficulties in meeting the information and knowledge needs of people living with limited health literacy due to the 
perception of time limitations. Moreover, the pharmacies of Convenience Sample 1 reported that they faced problems when trying to adapt their communication strategies and approaches to the specific functional, interactive and critical competencies of low health literate patients. All of the units of analysis stated that their employees were duly committed to providing patients with tailored and clear information about the attributes and the recommendations of over-the-counter drugs which were easy to access and to understand.

Overall, in both samples only a few pharmacies stated that the staff attended specific training activities aimed at enhancing employees' awareness of organizational health literacy issues. Besides, the senior management of the municipal pharmacies did not encourage the participation of the pharmacy staff in training activities in the field of health literacy, since they considered them not to be crucial for the improvement of organizational outcomes. Time and resource constraints were identified as the main barrier to the enhancement of the pharmacies' sensitivity to literacy.

\section{Discussion}

The pharmacies involved in this study reported a high awareness of organizational health literacy-related issues. Interestingly, the units of analysis showed high scores with regard to print information materials, clear verbal communication, and sensitivity to literacy. Confirming the insights of the scientific literature which identifies the enhancement of the patient-provider relationship as a crucial step to establishing a link between health literacy and health outcomes (von Wagner et al., 2009), the findings of this paper revealed that pharmacies paid particular attention to oral interactions between the pharmacy staff and patients. In fact, pharmacists are likely to detect and meet the special information needs of low health literate patients, thus compensating for the propensity of physicians to overestimate individual health literacy skills (Kelly and Haidet, 2007).

In spite of these considerations, it seems that the organizational commitment of pharmacies to the enhancement of organizational health literacy is still poor (Palumbo and Annarumma, 2015). The units of analysis included in this study were consistent in reporting that time limitations and lack of interactive and linguistic skills were the most significant barriers to the establishment of adequate relationships with patients, thus confirming what has been found in previous research (Tarn et al., 2006). This is especially true when patients have a strong need for timely and relevant health information, since they face multiple diseases and have to comply with different medication treatments (Edwards et al., 2015). However, most of the units of analysis reported that they were unable to provide patients with tailored health information materials in order to improve their ability to navigate the health care service system.

Several additional considerations could be drawn from the comparison between the units of analysis of the two samples which were built for this study, emphasizing both differences and similarities. An insightful
Carmela Annarumma Rocco Palumbo Mauro Cavallone Who empowers whom? The role of organizational health literacy in 
sinergie Vol. 35, N. 104, 2017

reflection could be developed dealing with pharmacies' willingness to increase the quantity and the quality of the information provided to patients. On the one hand, the units of analysis were found to be committed to improving their support to people living with limited health literacy. On the other hand, these initiatives were mainly led by individual employees, while they lacked institutional legitimation. This situation was especially common among the pharmacies that operated in the regional sub-system suffering from financial distress, where the scarcity of available resources did not allow senior management to pay adequate attention to the promotion of organizational health literacy. On the contrary, the units included in Convenience Sample 2 revealed greater propensity for enhancing the quality and the quantity of information in order to support patients in effectively handling health-related issues.

In line with these arguments, the training of pharmacy staff that aimed at boosting individual interactive skills appears to be a fundamental ingredient of the recipe for better patient-provider interactions. However, only a few pharmacies reported involving their employees in training activities in the fields of communication and health literacy. This finding is striking, since most of the pharmacies were consistent in perceiving clear verbal communication as a strategic tool for improving the organizational ability to establish co-creating relationships with patients. In particular, interactive skills allow the pharmacy staff to anticipate and meet the special information needs of four categories of patients at special risk of limited health literacy: 1) older adults; 2) people with a low level of education; 3) the disadvantaged population; and 4) immigrants who are not able to properly function within the health care service system.

With specific regard to the latter, the number of immigrants currently living in Italy is rapidly growing, as a result of the dramatic growth in the rates of three main categories of immigration: family class, economic immigrants, and refugees (Cavallone, 2007). Since pharmacies operate as an important point of contact between patients and the health care service system and act as critical patient navigators, they should enhance their interactive skills in order to better support immigrants in navigating the health environment. To achieve this aim, tailored communication strategies and tools should be devised and implemented by improving the ability of pharmacies to deal with non-Italian speaking patients. They should provide customized messages, supported by translations in other languages (i.e. English first) and non-verbal or para-verbal components. Delving into these arguments, it is worth noting that the item of the survey which showed the lowest average value $(\mu=5.5)$ was the statement: "the pharmacy provides ad hoc services to patients for whom Italian is a second language or for non-Italian speaking patients". Therefore, there is a strong need to fill the gap between the special information needs of immigrants and the ability of pharmacies to establish a friendly and comfortable relationship with them.

It is interesting to point out that the pharmacies that operated in the regional sub-system suffering from financial stress performed better as compared with their counterparts operating in the virtuous subsystem in four items of the survey: 1) patient counselling; 2) employees 
involvement in specific training courses in the field of print information design and delivery; 3 ) ability to establish a friendly relationship with nonItalian speaking patients; and 4) introduction of tailored communication strategies to deal with people living with problematic health literacy skills. These findings should be considered as a hint of the change that is affecting the units of analysis. Their strong awareness of health literacy-related issues could be conceived as a signal of their willingness to improve their strategies and operations in an attempt to anticipate and meet the growing needs of the served population.

The pharmacies included in Convenience Sample 2 were consistent in achieving higher scores as compared with their counterparts of Convenience Sample 1 in both the: "use of brochures and pamphlets to provide patients with adequate information on the services offered by the pharmacy" and the "availability of a private space to discuss confidential topics with patients". On the one hand, these findings suggest a greater entrepreneurial propensity of the pharmacies that operated in the virtuous regional sub-system, which is echoed by a wider availability of financial resources that could be addressed to improve organizational health literacy; on the other hand, they imply greater attention to the implicit information needs of patients.

For the sake of argument, the "counselling corner", which was found to be common among the pharmacies of Convenience Sample 2, is a catalyzer for the establishment of friendly, comfortable and co-creating relationships between patients and the pharmacy staff, thus increasing the ability of the latter to anticipate and satisfy the expectations of the former. From this point of view, the greater ability of the pharmacies that operated in the virtuous region to support patients who had to deal with high-risk situations, including care transitions, substantiates the worthiness of the inclusion of these issues in the design of pharmacies' organizational and communicational framework. These results confirm the value added by the ability of pharmacies to establish a friendly and co-creating relationship with patients, which is not merely aimed at the sale of drugs and medication, but also concerns patients' ability to properly function within the health care service system.

The findings of this paper should be read in light of its main limitations. Since the research concerned two convenience, non-representative samples of pharmacies operating within the INHS, it is not possible to claim the generalizability of the results discussed above. However, this study was able to provide several intriguing insights into the awareness of organizational health literacy of Italian pharmacies, emphasizing the similarities and the dissimilarities between entities operating in different regional sub-systems. The decision to focus on the staff's self-perception of organizational health literacy, ignoring both the environment and the patients' perspectives, affected the reliability of this research. Nevertheless, it managed to shed the light on the importance of organizational health literacy within Italian pharmacies, paving the way for further conceptual and empirical developments. Future efforts will be addressed at expanding this study to a representative sample of Italian pharmacies in order to strengthen the validity and the reliability of the research.
Carmela Annarumma Rocco Palumbo Mauro Cavallone Who empowers whom?

The role of organizational health literacy in empowering patients 


\section{sinergie}

Vol. 35, N. 104, 2017

\section{Conclusions}

The relevance of this paper is twofold, suggesting both conceptual and practical implications. With regard to the former, organizational health literacy is becoming a key issue for the future of pharmacies, emphasizing their role as patient navigators. Scholars should be encouraged to examine the specific characteristics of organizational health literate pharmacies. In particular, the attributes of print information materials, verbal communication strategies and organizational sensitivity to literacy should be discussed for the purpose of increasing pharmacies' ability to support low health literate patients in navigating the health care service system.

The organizational health literacy of pharmacies should be sought at both the institutional and the managerial levels. On the one hand, the engagement of professional associations in the initiatives aimed at promoting pharmacies' organizational health literacy is critical for fostering the adoption of a health literate approach in reimagining the relationship between pharmacists and patients. With specific regard to the Italian context, the Federation of the Orders of Italian Pharmacists (FOFI) could play a significant role in promoting the sensitivity of literacy to its associates, thus encouraging the involvement of pharmacies in the appropriate functioning of the health care service system. In fact, pharmacies should be understood as a critical knot of the local health care environment, which supports the patients in navigating the health system properly and in matching the levels of care they access with their specific health-related needs.

Finally, organizational health literacy should be conceived as a core idea inspiring the activities of all pharmacies' human resources. In other words, health literacy should be dealt with as a driver to raise awareness of the pharmacy's role in enhancing the effectiveness and the appropriateness of the health care service system. Accordingly, the willingness to improve the level of organizational health literacy should be inspired by a systemic approach. Adhering to these arguments, pharmacists would experience a significant evolution of their role. Rather than acting merely as drug sellers, they would represent critical mentors of their patients, providing them with advice and information that would allow an increased ability to effectively function within the health care environment. This will pave the way for momentous improvements in patients' quality of life and for the strengthening of the sustainability of the health care service system. In summary, the findings of this study suggest that better health outcomes, less expenditure and a higher level of self-care could be reached by means of meaningful efforts in advancing the friendliness and organizational health literacy of pharmacies.

\section{References}

ABRAMOWITZ P.W. (2009), "The evolution and metamorphosis of the pharmacy practice model", American Journal of Health-System Pharmacy, vol. 66, n. 16, pp. 1437-1446. 
ALGHURAIR S.A. (2012), "What elements of the patient-pharmacist relationship are associated with patient satisfaction?", Patient Preference and Adherence, vol. 6, n. 1, pp. 663-676.

ANDERSON R.M., FUNNELL M.M. (2005), "Patient empowerment: reflections Carmela Annarumma Rocco Palumbo on the challenge of fostering the adoption of a new paradigm", Patient Education and Counseling, vol. 57, n. 2, pp. 153-157.

ANNARUMMA C., PALUMBO R. (2016), "Contextualizing Health Literacy to Health Care Organizations: Exploratory Insights", Journal of Health Management, vol. 18, n. 4, pp. 611-624.

AUJOUlAT I., D'HOORE W., DECCACHE A. (2007), "Patient empowerment in theory and practice: polysemy or cacophony?", Patient Education and Counseling, vol. 66, n. 1, pp. 13-20.

BAKER D.W. (2006), “The Meaning and the Measure of Health Literacy”, Journal of General Internal Medicine, vol. 21, n. 8, pp. 878-883.

BODDEWYN J. (1970), "Comparative Management Studies: An Assessment", Management International Review, vol. 10, n. 2-3, pp. 3-11.

BOVAIRD T., LÖFFLER E. (2009), Public Management and Governance, Routledge, London.

BRACH C., DREYER B., SCHYVE P., HERNANDEZ L., BAUR C., LEMERISE A.J., PARKER R. (2012), Attributes of a health literate organization, The National Academies Press, Washington, DC.

BRAVO P., EDWARDS A., BARR P.J., SCHOLL I., ELWYN G., MCALLISTER M. (2015), "Conceptualising patient empowerment: a mixed methods study", BMC Health Services Research, vol. 15, n. 1, pp. 252-265.

CAMERINI A.L., SCHULZ P.J. (2015), "Health Literacy and Patient Empowerment: Separating Conjoined Twins in the Context of Chronic Low Back Pain", PLOS-One, vol. 10, n. 2, e0118032.

CAVALLONE M. (2007), "Gestire la comunicazione di marketing nella società multiculturale: problemi aperti e implicazioni per il management”, Mercati e Competitività, vol. 1, n. 1, pp. 95-117.

COLLINS S., BARBER A., SAHM L.J. (2014), "Pharmacist's Counselling Improves Patient Knowledge Regarding Warfarin, Irrespective of Health Literacy Level", Pharmacy, vol. 2, n. 1, pp. 114-123.

COLTMAN T.D., MIDGLEY D.F., VENIAK S. (2008), "Formative versus reflective measurement models: Two applications of formative measurement", Journal of Business Research, vol. 61, n. 12, pp. 1250-1262.

DIAMANTOPOULOS A., SIGUAW J.A. (2006), "Formative versus reflective indicators in organizational measure development: a comparison and empirical illustration", British Journal of Management, vol. 17, n. 4, pp. 263-282.

FOX-WOLFGRAMM S.J. (1997), “Towards Developing a Methodology for Doing Qualitative Research: The Dynamic-Comparative Case Study Method", Scandinavian Journal of Management, vol. 13, n. 4, pp. 439-455.

EDWARDS M., WOOD F., DAVIES M., EDWARDS A. (2015), “'Distributed health literacy': longitudinal qualitative analysis of the roles of health literacy mediators and social networks of people living with a long-term health condition", Health Expectations, vol. 18, n. 5, pp. 1180-1193.

FUMAGALLI L.P., RADAELLI G., LETTIERI E., BERTELE’ P., MASELLA C. (2015), "Patient Empowerment and its neighbours: Clarifying the boundaries and their mutual relationships", Health Policy, vol. 119, n. 3, pp. 384-394. 


\section{sinergie}

Vol. 35, N. 104, 2017

FUNNELL M.M., ANDERSON R.M., ARNOLD M.S., BARR P.A., DONNELLY M., JOHNSON P.D., TAYLOR-MOON D., WHITE N.H. (1991), "Empowerment: an idea whose time has come in diabetes education", The Diabetes Educator, vol. 17, n. 1, pp. 37-41.

GEORGE A.L. (1979), "Case studies and theory development: The method of structured, focused comparison", in Lauren P.G., Diplomacy: New approaches in history, theory, and policy, Free Press, New York, NY, pp. 4368.

HERNANDEZ L.M. (2013), Health Literacy: Improving Health, Health Systems, and Health Policy Around the World: Workshop Summary, The National Academies Press, Washington, D.C.

JACOBSON K.L., GAZMARARIAN J.A., KRIPALANI S., MCMORRIS K.J., BLAKE S.C., BRACH C. (2007), Is Our Pharmacy Meeting Patients' Needs? A Pharmacy Health Literacy Assessment Tool User's Guide, Agency for Healthcare Research, Rockville, MD.

JENNINGS B.T., MCADAM MARX C. (2012), "Implementation of a pharmacistmanaged diabetes program”, American Journal of Health-System Pharmacy, vol. 69, n. 22, pp. 1951-1953.

JOHNSON J.L., MOSER L., GARWOOD C.L. (2013), "Health literacy: A primer for pharmacists", American Journal of Health-System Pharmacy, vol. 70, $\mathrm{n}$. 11, pp. 949-955.

KELLY P.A., HAIDET P. (2007), "Physician overestimation of patient literacy: A potential source of health care disparities", Patient Education and Counseling, vol. 66, n. 1, pp. 119-122.

O’NEAL K.S., CROSBY K.M., MILLER M.J., MURRAY K.A., CONDREN M.E. (2013), "Assessing health literacy practices in a community pharmacy environment: Experiences using the AHRQ Pharmacy Health Literacy Assessment Tool”, Administrative Pharmacy, vol. 9, n. 5, pp. 564-596.

PALUMBO R. (2016a), "Contextualizing co-production of health care: a systematic literature review", International Journal of Public Sector Management, vol. 29, n. 1, pp. 72-90.

PALUMBO R. (2016b), "Designing health-literate health care organization: A literature review", Health Services Management Research, vol. 29, n. 3, pp. 79-87.

PALUMBO R., ANNARUMMA C. (2015), "Exploring the Organizational Health Literacy of Municipal Pharmacies: The Quest for a Health Literate Organizational Environment", Toulon-Verona Conference "Excellence in Services", August, $31^{\text {st }}$ - September, $1^{\text {st }}$ 2015, Palermo, Italy, p. 401-416.

PALUMBO R., ANNARUMMA C., ADINOLFI P., MUSELlA M. (2016a), “The missing link to patient engagement in Italy The role of health literacy in enabling patients", Journal of Health Organization and Management, vol. 30, n. 8, pp. 1183-1203.

PALUMBO R., ANNARUMMA C., ADINOLFI P., MUSELlA M., PISCOPO G. (2016b), "The Italian Health Literacy Project: Insights from the assessment of health literacy skills in Italy", Health Policy, vol. 120, n. 9, pp. 1087-1094

PRIGGE J.K., DIETZ B., HOMBURG C., HOYER W.D., BURTOND J.L. (2015), "Patient empowerment: A cross-disease exploration of antecedents and consequences", International Journal of Research in Marketing, vol. 32, n. 4, pp. 375-386. 
ROSENTHAL M., MORALES E., LEVIN S., MURPHY L. F. (2014), “Building a team to fight diabetes: Pharmacy students' perceptions about serving as patient navigators", Currents in Pharmacy Teaching and Learning, vol. 6, n. 4, pp. 595-604.

SARTO F., VERONESI G., KIRKPATRICK I., CUCCURULLO C. (2016), "Exploring regionalism in public management reforms: the case of the Italian hospital sector", Policy and Politics, vol. 44, n. 4, pp. 525-545.

SCHULZ P.J., NAKAMOTO K. (2013), "Health literacy and patient empowerment in health communication: the importance of separating conjoined twins", Patient Education and Counseling, vol. 90, n. 1, pp. 4-11.

SWAIN S.D., WEATHERS D., NIEDRICH R.W. (2008), "Assessing Three Sources of Misresponse to Reversed Likert Items", Journal of Marketing Research, vol. 45, n. 1, pp. 116-131.

TARN D.M., HERITAGE J., PATERNITI D.A., HAYS R.D., KRAVITZ R.L., WENGER N.S. (2006), "Physician communication when prescribing new medications", Archives of Internal Medicine, vol. 166, n. 17, pp. 1855-1862.

VON WAGNER C., STEPTOE A., WOLF M.S., WARDLE J. (2009), "Health Literacy and Health Actions: A Review and a Framework from Health Psychology", Health Education and Behaviour, vol. 36, n. 5, pp. 860-877.

WANG R.H., HSU H.C., LEE Y.J., SHIN S.J., LIN K.D., AN L.W. (2016), "Patient empowerment interacts with health literacy to associate with subsequent selfmanagement behaviors in patients with type 2 diabetes: A prospective study in Taiwan”, Patient Education and Counseling, vol. 99, n. 10, pp. 1626-1631.

WEAVER N.L., WRAY R.J., ZELLIN S., GAUTAM K., JUPKA K. (2012), “Advancing organizational health literacy in health care organizations serving highneeds populations: a case study", Journal of Health Communication, vol. 17, n. S3, pp. 55-66.

WEIJTERS B., CABOOTER E., SCHILLEWAERT N. (2010), “The effect of rating scale format on response styles: The number of response categories and response category labels", International Journal of Research in Marketing, vol. 27, n. 3, pp. 236-247.

WILlIS C.D., SAUL J., BITZ J., POMPU K., BEST A., JACKSON B. (2014), "Improving organizational capacity to address health literacy in public health: a rapid realist review", Public Health, vol. 128, n. 6, pp. 515-524.
Carmela Annarumma Rocco Palumbo Mauro Cavallone Who empowers whom? The role of organizational health literacy in empowering patients

\title{
Academic or professional position and contacts
}

\author{
Carmela Annarumma \\ Research Fellow of Management \\ University of Salerno - Italy \\ e-mail: cannarumma@unisa.it \\ Rocco Palumbo \\ Research Fellow of Management \\ University of Salerno - Italy \\ e-mail: rpalumbo@unisa.it \\ Mauro Cavallone \\ Associate Professor of Management \\ University of Bergamo - Italy \\ e-mail: mauro.cavallone@unibg.it
}

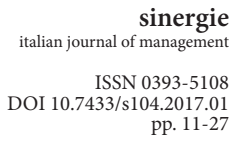

FONDAZIONE CUEIM 